\title{
Affective and Cognitive Dimensions of Trust in Communication $^{1}$
}

\author{
Barna KOVÁCS \\ Sapientia Hungarian University of Transylvania \\ Cluj-Napoca, Romania \\ e-mail: kovacsbarna@ms.sapientia.ro
}

\begin{abstract}
Based on the complexity of communication acts, the paper presents how affective and cognitive aspects are intertwined. First of all, the context of trust and the conditions of its appearance are examined. It is followed by an analysis of trust as an attitude which reveals the difference between contractual approaches and alliances. The relationship between communication and trust is presented by the illocutionary acts. As a result of the analysis, trust can be conceived as a positive attitude of expectation, where one person relies on the assumed good faith, suitability, and sensitivity of the other person, where, although vulnerable, the one who trusts counts on the fact that the trusted person will not abuse his/her position but rather provide assistance to his/her best knowledge in a given area. Cognitive trust is reinforced if the proper data are available, understandable, fit into prior knowledge, and anticipate the possible forms of operation. With affective trust, the issue is not data quality and quantity but rather the way how they are presented.
\end{abstract}

Keywords: trust, distrust, affective trust, cognitive trust, speech act theory

\section{Introduction}

Trust is a versatile concept subject to various interfaces. It has a certain meaning in the case of couples and yet another in the parent-child relationship. Trust in a physician has a completely different meaning than trust in science, politics, environment, or weather forecast. Trust has a wide span starting from the most personal level, i.e. self-confidence, up to the most encompassing network of contacts, i.e. social trust. According to the multifariousness of manifestations, trust fits into the current environment. This results in a diversified content requiring communication structures to be reviewed.

Trust is inseparable from the concept of distrust; thus, in my interpretation, the relationship between these two is a displacement along a vertical axis, and

1 Funded by the Hungarian Academy of Sciences' Domus programme, 2020. 
it increases or decreases depending on the risk. Any decrease in terms of trust is an increase in terms of distrust and vice versa. Any increase in terms of trust is a decrease in terms of risk and vice versa. This is the cognitive aspect of trust, taking into account the risk factors and calculating probability. However, there is also an affective dimension, which enhances or prevents the development of trust. Using communication acts, my review presents how affective and cognitive aspects are intertwined. First of all, I examine the trust context, then the relationships developed relying on trust, and, finally, I show the essential characteristics of affective and cognitive trust.

\section{Trust Context}

A distinction shall be made between trust in the context of which we acquire information and trust in information itself. According to the principle of our navigating the world, trust structures, preconceptions, and conscious actions are a prerequisite. This is facilitated, for instance, by family, neighbourhood, kinship, or friendship, i.e. all such relationships which are determining factors. It relies also upon them, not only upon the direct consciousness that one can think or feel that s/he is capable of doing something. This is an extended directness since not only one's own conscious activity is given but also the context of one's life-world through the system of relationships. Although we experience this extended directness as something a priori, it is not unproblematic since the basis of the resulting evidence or beliefs is often fragile.

Our navigating the world is enabled by a context or system within the framework of which we feel comfortable and familiarized, i.e. which makes orientation possible for us in our own media. Such contexts may be totally personal, for instance one's deep conviction or value system. By way of example, external systems include social institutions starting from school or bakery through police or pub to an Internet browser or the Facebook platform. All these act as infrastructures, as networks. Paths and tracks are created to function as a communicative system.

It is this network that provides information to be processed using our system. Is it comprehensible for us or not; does it reach our sensitivity threshold or not; do we perceive it as being attractive or repelling? Information represents the surface, and it is processed on grounds of the system. Thus, the question of how the system works is at least as significant as the very communication of the information. The perceived information is the input, while the information which is understood is the output, and processing takes place within the framework of a system. According to this approach, trust mirrors cognitive and affective trust in the context, i.e. in the system. Cognitive trust means the knowledge I have about 
the operation of a certain context. Affective trust means the entirety of my prior experiences, expectations, and preconceptions, which determines my attitude towards the given context. I either accept, for instance, social media as a system and appreciate the opportunities provided thereby or not.

The system is intended to be used in a very large sense, starting from the operational system of consciousness to the Facebook platform system. One can ascertain that it is a communicative system where there is a communicator and a recipient, there is intention, there is channel (infrastructure), and most of all there is a context. The actual question is: how does a relationship or an attitude towards something or somebody develop? We live in relationships, our mutual being is based on relationships, and trust is a quality attribute of relationship. Consequently, something exists as subject to my attitude, i.e. the attitude develops it, just as it develops me.

\section{Trust as Attitude}

Trust equally means self-confidence, confidence in the world, and confidence in relationships. This enumeration gives rise to a possible summarization of the trust theories by differentiating the reference aspects of relationships (Dormandy, 2020: 1). In the case of a three-party trust, somebody trusts in someone else concerning something: for instance, somebody asks another person to buy something for him/her. This is the most frequent and most analysed approach of trust. In the case of a two-party trust, there is a trust relationship without any actual targeting, i.e. it is the relationship itself that carries the trust. Between acquaintances, this type is the most common occurrence, no matter whether the relationship is familial, cordial, or of another nature. One-party trust means selfconfidence, where the person deems that his/her own position is safe and wellfounded. These three factors mutually influence each other. Self-confidence is a prerequisite for being able to develop relationships based on trust and for trusting someone with regard to something.

Basically, I intend to pursue an interpretation focused on three-party and twoparty trusts. A three-party trust may be regarded as being based on a contract since it is accountable and conditional. Also, it can be construed as a market model since a delivery-reception can take place if somebody places trust in someone else and has certain expectations in exchange. No buying and selling are conceivable if the buyer fails to trust the merchandise to some extent or if the seller fails to accept the means of payment (except in cases where the purchase takes place, for instance, due to some constraint).

Two-party trusts refer to interpersonal relationships. The trust invested in interpersonal relationship is a prerequisite of the contract; however, at a more 
basic level, it also means an alliance not having necessarily any subject or purpose or actual gains. Alliances are also set up under certain conditions; moreover, they are accountable and reinforceable, just as contracts are. Contracts are governed by rationality, covering as many details as possible. Alliances, namely relationships between two persons or groups, are governed by affectivity, which makes it possible for the relationship to even develop. As such, an alliance is a more extended contractual form. It is possible to envisage situations where contracts are concluded by and between perfect strangers; however, alliances presuppose a deeper acquaintanceship where the community of interests and basic principles are mutually accepted.

\section{Communication, Action, Trust}

How can we get to genuine knowledge? What may put an end to an infinite suspicion? It is not only about the evidence of truth which can be comprehended by pure reason but also about an affective attitude. How can we even stand up, start walking, go to bed, dream, speak, or listen? In keeping with Luhmann, we could say that no action can take place unless we trust ourselves and our environment (Luhmann, 1979). Getting up in the morning presupposes that I am able to move, going to work presupposes that I accept the traffic rules and I am confident that others do the same as well.

The focal point of the review is speaking, a manifestation for the interpretation of which Austin's speech act theory is of assistance (Austin, 1962). Locution is the trust in the language. Illocution is the trust in the act. Perlocution is the trust elicited by the utterance, i.e. the effect of the speech. Under these terms of interpretation, the issue of trust or distrust may appear at all three levels.

Firstly, there is the trust in relying on the language, under the form of locution. Most frequently, we experience this as the question whether we succeeded to communicate something in a proper form. It is not only about observing syntactic and semantic rules but also about assuming the expression act. We recognize this phenomenon in situations where we vacillate to say something or not in an alien environment in a foreign language. It is subject to this decision that a manifestation takes place.

Secondly, illocution refers to an act accomplished in speech. Terestyéni presents in keeping with Austin the most common acts of speech as forms of illocution. Examining these, we can easily find out that an important component of the speech acts, illocutionary force is the displacement according to the trustdistrust axis (Terestyéni, 2006: 80-81). When promising, the communicator pledges himself/herself to do something, i.e. asks for the recipient's trust, stating his/her own capacity (to keep the promise) at the same time. 
In the asking act, the communicator depends on the recipient, who feels impelled to do something, trusting the communicator's genuine request.

In the case of commands, the recipient trusts the commander as the communicator trusts the execution. A power relation is also involved here since any failure to obey the order results in punishment, and the communicator is liable for what was commanded.

In the informing act, the facts made known to the recipient are accepted only if the recipient trusts the communicator and the communicator is confident that the information is properly processed by the recipient.

Through the statement, the communicator commits himself/herself to the truthfulness of the subject matter of the statement as well as to the fact that s/he can also prove the same, while the recipient considers and checks upon the truthfulness of the statement according to the trust level.

By way of authorization, the recipient becomes entitled to do something, enjoys trust, and accepts the authorizer's authority, while the communicator trusts the recipient.

In a contract, the communicator and the recipient mutually pledge themselves to do something and mutually confer trust to each other under certain conditions endeavoured to be met by both parties.

Accusation means loss of trust, holding to account, where the communicator imputes an unfavourably appreciated deed to someone and assumes liability for the proper formulation of the imputation. The accused person finds himself/ herself in a situation where s/he has to prove the extent of his/her liability in terms of the deed which represents the subject matter of the accusation, i.e. has to restore the shattered trust. The recipient is the one who considers whom to trust most, the accuser or the accused?

It is not only in speech acts that the role played by trust is demonstrable but also according to the meaning and purpose of the illocution. Following Searle's typology, Terestyéni highlights the following illocutionary essentials (Terestyéni, 2006: 82). The essence of the speech act assertive is that the hearer commits himself/herself to the truthfulness of the sentence, i.e. a cognitive trust is developed in terms of the given information. The essence of the illocutionary directives is to cause the hearer to adapt his/her behaviour according to the proposition content, i.e. the effect becomes evident when the hearer accepts what the communicator said. Commissives are such commitments on the communicator's part through which s/he warrants the hearer that the act shown in the proposition content is executed. The illocutionary essence of expressives refers to warranting the sincerity of the speech act. In speech declarations, the essence is eliciting some kind of change in the world, exerting an effect. Someone tells somebody something in expectation of achieving a certain effect. Except for the speech act assertives, presupposing affective trust is unavoidable. 
Thirdly, perlocution refers to the audience's increase or decrease of trust due to the speech act. We are thinking in models regulated on an illocutionary level, where such expectations and obligations are formulated towards the participants, which, once accomplished, result in a valid manifestation, so that the rationalization function plays a central role. In the case of perlocution, there appear sentiments, beliefs, and affective dimensions of trust, which are driven not only by convention. This triple division of the speech act offers a comprehensive image of the manifestation. In the context of communication and action, we learn more about how trust operates. The relation between trust and communication is enriched by a more explicit meaning. Manifestations develop if trust is given. Manifestations result in increasing or decreasing trust.

Although Austin does not use the concept of trust in How to Do Things with Words, one can conclude that it is about a specific element of the speech acts (Austin, 1962). The basic communicative aspect of trust is when someone tells somebody something. Trust is presupposed by this act in itself. The communicator hopes to formulate the statement so that the recipient understands its content and it has an impact on the recipient. Therefore, trust related to one's own abilities is present in the manifestation, a trust related to the community of the language, the trust in the speech act, the trust in the recipient's attention and in processing the information as well as the trust in the effect of the speech.

Taking three examples, I illustrate the speech act development according to trust.

Let us imagine the following situation at the foot of the Eiffel tower. A tourist's phone battery has just gone flat, so the tourist cannot contact the person whom he must meet. The tourist asks a stranger to kindly lend him his/her phone, disassembles it in order to change the removable SIM card, and then returns it as soon as the call has ended. The situation is more difficult since s/he does not speak any foreign languages.

This person steps over a boundary, which involves addressing a stranger, and then yet another one, which is due to not knowing the foreign language. This locution is a manifestation of self-confidence at the same time. The request (illocution) is formulated in a gesture language and places trust in the recipient's understanding. The recipient intercepts the message, steps over his own stimulus threshold, not sensing it as a risk source, a common language is developed, and as soon as this is understood, a response is formulated. Since the attempt was successful, trust is confirmed in the communicator's case and, as soon as the phone is returned, the recipient may enjoy the confirmation of the fact that s/he was in a position to help (perlocution).

Let us see an example of conventional mode of speech. Whenever someone receives a piece of information that can be easily comprehended although s/he dissociates him-/herself from it, this is often manifested using expressions such as 
"I do not understand" or "I do not know". Besides the word-by-word interpretation of the expression meaning that s/he simply does not have the answer, there are also other possibilities. It may well happen that s/he is in an emotional disposition which makes incomprehensible for him/her the given information or message, i.e. the content which is accounted for has not even crossed his/her stimulus threshold. It is characteristic for students that whenever they complain about the "absolutely incomprehensible" nature of a subject matter, it is difficult to discern whether understanding the content or the lecturer is the source of the issue, or they happen to be in an emotional disposition which makes concentration difficult for them. The statement involves locution, and the explanation act involves illocution; however, there is no apprehension, so that the effect (perlocution) is low since a wall is built in between the communicator and the recipient. Consequently, trust is frozen between the communicator and the recipient.

Besides the "I do not know" dead-end strategy, the "diverting to side roads" strategy is also possible. The side road aspect is reached in that the content of the message of communication gets a totally different interpretation than originally intended. This may readily take the form of telling a story. The simple message (locution) "you look good this morning" is basically a confirmation (illocution). At the same time, it may be formulated as expectation or, due to an unthought-of connotation, it elicits an effect which is quite the contrary to what is expected (perlocution), i.e. the look is not interpreted as a statement but rather as an expectation. The communicator's intent and the recipient's interpretation yield an entirely different result. Consent, cooperation, and togetherness is possible only provided that the two interpretations concord. This, however, can be achieved by continuous communication and trust-building efforts. In the present case, it is the very loss of trust which emerges as a winner.

The first example showed how a challenge resulted in assuming risks and yielded a positive outcome. The "I do not know" attitude of dissociation meant postponing the risk. Finally, in the example for misunderstanding, risk assumption ended up in a negative outcome. Why is this difference between the results?

According to my interpretation, the reasonably understandable core of the message reached various affective contexts. Affective context is a very broad term, which includes emotional affection and emotional intention. However, past, tradition, customs, all unclassified and voluntary attitudes, reflexes, aspirations, expectations, visions, and preconceptions are also present, carrying an affective interest, attitude, and intention.

Diverting to side roads leads to discord, i.e. the speech fails, ending up in a disagreement/conflict. There are many ways how conflicts may arise, but what I would like to reveal here is that even the simplest commonplace sentence can initiate the development or the destruction of the communicator's and the recipient's already existing trust. 
Under such circumstances, there are two solutions; however, neither can be regarded as being perfect. On the one hand, there is the shortcut way, which would be ideal but is such an abstract form, so abstract from actual happenings and from the flesh-and-blood reality of the human relationships that it cannot be regarded as self-evident. This is the place for permanent evidence, the realm of genuine, valid discernments, which presupposes a formalized language where everything is univocal.

On the other hand, there is the roundabout way which tries to wrap up what has happened, taking into account the affective aspects, the context, the antecedents, etc. Its greatest disadvantage is that judgment, just as action and decision, is difficult to be achieved. It shall always be taken into account that something might be missing, the results are probabilistic, and thus ambivalence and ambiguity are always present.

\section{Affective and Cognitive Features of Trust}

A particular feature of trust is that it can be regarded as a cognitive and affective happening at the same time (Baier, 1994). We cannot categorize it unequivocally, only on one side. The cognitive side is about rationally admitting the necessity and the risk of the trust. I am unable to check upon the validity of all information; thus, I am relying on the experts' opinion. Luhmann describes the complexity of the world, which can be reduced by trust (Luhmann, 1988). This also involves taking a risk and assuming a role in a play where we assign a certain extent of trust to the challenges posed by ambiguous outcomes encountered by us, based on rational appreciations. Pettit seems to find the cunning of trust in that the one who trusts expects that the trustee will not break the promise since otherwise society would consider the trustee unreliable (Pettit, 1995). Thus, the relationship between the two parties can be considered as being valid in such a social environment where there is a third party who is watching and judging.

Following this approach, it is obvious to construe the question of trust based on the supply-demand concepts. It is difficult for us to regard trust as a constant value, i.e. the nature of trust is subject to an increasing or decreasing displacement according to risk. Of course, trust is high if risk is low, and it is low if risk is high. At the point of impact between trust and risk, trust supply and trust demand meet. How can the equilibrium point be found, when can we speak about trust surplus and trust deficit?

Examining the trust concept in itself, one can readily find behind this rational sale-purchase the a priori givenness of either of the trust layers without which this meeting would not take place at all. Consequently, we have to assume such a trust level which serves our navigating the world. 
Another shortcoming of the model is that it is supposed to be general; however, one can easily realize that it can take a completely different form according to the subject matter of trust. It is not exactly the same whether it is about a close family member relating to whom the question of trust does not really arise or about a high risk factor stranger. This model can hardly explain how to relate to a stranger, how innovation is possible if trust does not break through the framework of habits.

The contradiction of trust resides in that a give-take is conducted on the basis of rational market terms on the one hand, and for affective considerations we go beyond the logic of these market terms on the other hand. In a parent-child relationship, for instance, using the market term logic would practically bring about terror or some kind of blackmail. This does not mean that there is no negotiation of a certain sort in the educational process but that what is at stake is completely different. Relating to the first case, one could say that it is the operating mode of social trust. In the second case, there is a one-person trust, where it is not the mutuality logic which acts in a positive or negative direction but rather the logic of support. Hence, we find the limits of trust relativity in personal trust, which has absolute values. The parent can look at the child trustfully even if the latter has just committed an outrageous act. A friend is able to be supportive even if s/he should deny an act according to all social conventions. The parent is not a dominator, a friend is not a trading customer, and the spouse is not a business associate. In this conceptualization, the first level can be regarded as a contract and the second one as an alliance.

The rational model allows us to work out game theory models; however, this can turn out to be too abstract when analysing actual human relationships. Obviously, there is a rational element in judging trust; however, the emotional disposition and the affective interests shall also be considered at the same time. Raising this question makes us go from the abstract extreme to the specific extreme, where we encounter case-by-case situations impossible to be generalized on a permanent basis. The topicality of this research is given by the fact that within a specific area of public life, namely in social media, all those mechanisms meant to influence voters and buyers through affective and emotional methods are readily recognizable. Phenomena such as fake news, posttruth, and echo chamber are all proofs that the most efficient way to influence opinions is through emotions and affective interests. This well-established mode of communication can be regarded as rationally fundamental; however, it is still necessary to understand the emotional and affective side of communication. By emotional dimension I mean that the recipient goes through experiencing fear, anger, rage, joy, etc. Basically, the affective dimension means an interest, i.e. the recipient is not untouched by what s/he sees, and that it has some kind of effect upon the recipient. Pursuant to Jones's conclusions, we can envisage an affective 
looping which acts in the sense of reinforcing or transforming a prior emotional state (Jones, 2019: 2).

Returning to our analysis concerning the trust context, relationships, and language, we find that both the affective side and the cognitive side are present. In examining the trust context, the very processing of the information requires the operation of the cognitive side, based on which we can make various decisions - for instance, we can rely on someone. However, the information context means an affective interest as well since in order to notice something our attention has to be drawn to it. Subject to the trustworthiness of the context, attention will be expressed in yet other forms, noticing yet other factors, and interpreting in yet other contexts the same. The "I am able" or the "I am unable" notion also involves an affective message, which creates or buries a world.

This latter notion means the formation of a self-affection, which in analysing the trust aspects took the form of self-confidence. In this part, we have explained the role of cognitive trust, which defines the three-party trust since conferring trust takes place on some kind of grounds. In the case of two-party trust, discussing the affective dimension was unavoidable because of the reliance upon a mutual interest in interpersonal relationships.

By virtue of the speech act theory, one may consider that the communication, action, and trust concepts can be interconnected. In analysing common speech acts, one can perceive trust as a component. The basic question of perlocution in our analysis is whether manifestation brings about an increase or a decrease in terms of trust. Obviously, the communicator's motivation can be deemed to be the fact that s/he is regarded as being trustful, and his/her motivation why s/he said whatever s/he said is accepted.

According to Luhmann, trust is a risky investment (Luhmann, 1979). The notion facilitated the intense economic interpretation and application of the trust concept. This analysis is aimed at highlighting the fact that trust has also an affective dimension besides the rationalizing interpretation. Jones (2019) has made two attempts to define trust from an affective viewpoint.

According to the first one, "trust is the optimism that the other person's benevolence and suitability will be extended to warrant our area of interaction, and, at the same time, it is the expectation that the trusted person is directly and favourably influenced by the fact that we are counting on him/her" (Jones, 1996: 4). In his second definition, Jones uses the concept of sensitivity instead of a benevolence, and leaves out the notion of expectation. "A trusts B in a D area of interaction if and only if A handles optimistically B's suitability and sensitivity to support him/her in the said area" (Jones, 2019: 4). 


\section{Conclusions}

Summarizing these definitions, trust can be construed as a positive attitude of expectation where one person relies on the assumed good faith, suitability, and sensitivity of the other person, where, although vulnerable, the one who trusts counts on the fact that the trusted person will not abuse his/her position but rather provide assistance to his/her best knowledge in a given area. The affective definition of trust involves the concept of optimism, good faith, sensitivity, and vulnerability, which reinforces the subjective side and makes trust highly malleable since these concepts are also difficult to be given a general definition within this context. At the same time, the affective definition does not exclude the definition regarded as being cognitive, but it rather emphasizes a peculiar dimension of risk.

Which are the distinctive features of cognitive and affective trust? Cognitive trust is reinforced if the proper data are available, understandable, fit into prior knowledge, and anticipate the possible forms of operation. With affective trust, the issue is not data quality and quantity but rather the attitude, the way how they are presented. The interdependence of the two forms is well recognizable. Failure to provide all information results in two possibilities: the communicator was either unaware of or wilfully omitted them. In the case of wilful omission, bad faith is supposed, which causes weakening in terms of trust. Based on our reasoning, we can ascertain that communicating the proper information will not suffice, but rather wording the message and the nature of the communicator's attitude are decisive. The form of communication can be regarded as efficient if it is capable of performing the information selection for the cognitive trust, and, at the same time, such form of communication is chosen and the communication takes place in such a way that the supposition of good faith is preserved.

\section{References}

Austin, J. L. (1962). How to Do Things with Words. Cambridge: Harvard University Press.

Baier, A. (1991). Trust and Its Vulnerabilities. In: Trust. The Tanner Lectures on Human Values. Princeton University, March 6-8. https://tannerlectures.utah. edu/_documents/a-to-z/b/baier92.pdf (accessed on: 09 September 2020).

Dormandy, K. (2020). Introduction. An Overview of Trust and Some Key Epistemological Applications. In: Dormandy, K. (ed.), Trust in Epistemology. New York-London: Routledge.

Jones, K. (1996). Trust as an Affective Attitude. Ethics 107.

(2019). Trust, Distrust and Affective Looping. Philosophical Studies 176. 
Luhmann, N. (1979). Trust. In: Luhmann, N., Trust and Power. Chichester-New York-Brisbane-Toronto: John Wiley and Sons.

(1988). Familiarity, Confidence, Trust: Problems and Alternatives. In: Gambetta, Diego (ed.), Trust: Making and Breaking Cooperative Relations. Oxford: Basil Blackwell.

Pettit, P. (1995). The Cunning of Trust. In: Philosophy and Public Affairs 24: 3.

Terestyéni, T. (2006). Kommunikációelmélet. A testbeszédtól az Internetig [Theory of Communication. From Body Language to Internet]. Budapest: Typotex.

\section{Cite as:}

Kovács, B. (2020). Affective and Cognitive Dimensions of Trust in Communication. Acta Universitatis Sapientiae, Communicatio 7: 13-24. DOI: 10.2478/ auscom-2020-0002. 